\title{
MODEL PEMANENAN DAN PENGOLAHAN AIR HUJAN MENJADI AIR MINUM
}

\author{
Amalia Nurdin $^{1}$ Desi Lembang ${ }^{2}$ Kasmawati $^{3}$ \\ ${ }^{1}$ Universitas Sulawesi barat, Indonesia \\ Email : amalianurdin@unsulbar.ac.id \\ ${ }^{2}$ Politeknik Negeri Fakfak, Papua Barat Indonesia \\ Email :desilembang5@gmail.com \\ ${ }^{3}$ Universitas Muhammadiyah Makassar, Indonesia \\ Email :kasma08@unismuh.ac.id
}

\begin{abstract}
ABSTRAK
Penelitian ini dilatarbelakangi karena kurangnya air bersih pada lokasi penelitian, pemanfaatan sumber daya air yang tidak maksimal dan kurangnya kemampuan warga dalam memenuhi kebutuhan air minum. Tujuan penelitian ini diharapkan dapat mengetahui berapa besar potensi air hujan yang dapat di panen, bagaimana kualitas air hujan setelah pengolahan dan bagaimana kuantitasnya. Besarnya potensi air hujan yang akan di panen ditentukan dengan menggunakan data rata-rata curah hujan yang terjadi pada lokasi penelitian sedangkan pada sistem pengolahan air hujan ini digunakan metode eksperimen. Hasil dari penelitian ini didapatkan volume potensi hujan yang terjadi pada lokasi penelitian adalah $284,75 \mathrm{~mm} /$ bulan dengan kualitas air hujan setelah pengolahan dengan melalui proses penyaringan dan penambahan sodium bicarbonate 1gr/10liter menghasilkan kualitas air hujan yang memenuhi syarat sebagai air minum. Sebelum dilakukan penampungan air hujan sebaiknya di lakukan pembersihan awal (first flushing) agar debu dan sedimen yang menumpuk selama musim kering tidak ikut tertampung dan sebelum dilakukan pengolahan sebaiknya tangki berisi air hujan sebanyak \pm 2000 liter agar terjadi pengenceran terhadap parameter yang berpengaruh terutama pada parameter warna dan kekeruhan.
\end{abstract}

Kata Kunci : Model Pengolahan Air Hujan, Sodium Bicarbonat

\section{ABSTRACT}

This research is motivated because of the lack of clean water at the study site, the utilization of water resources is not optimal and the lack of ability of citizens to meet the drinking water needs. Therefore, conducted a pilot model of rainwater harvesting and processing into drinking water, where this pilot carried out at one of the houses on the island of Lae-Lae. The purpose of this study are expected to know how big the potential of rainwater can be harvested, how the quality of rainwater after treatment and how quantity. The magnitude of the potential rainwater harvest will be determined using average data of rainfall that occurred in the study site, while the rain water treatment system is used the experimental method. Results from this study, the potential volume of rainfall that occurred in the study site is $284,75 \mathrm{~mm} /$ month with rain water quality after processing through the screening process and the addition of sodium bicarbonate $1 \mathrm{~g} / 10$ Liter produce the quality of rainwater that qualify as drinking water. Before the rainwater harvesting should be done cleaning the beginning (first flushing) so that dust and sediment that has accumulated during the dry season did not participate accommodated and before processing should tank rainwater as much as \pm 2000 liters enable the dilution of the parameters that affect especially the color parameters and turbidity.

Keywords: Model Processing, Rain Water, Sodium Bicarbonate

\section{PENDAHULUAN}

Ketersediaan air merupakan hal utama di berbagai belahan dunia termasuk di kepulauan kecil yang ada di Indonesia salah satunya Pulau Lae-Lae. Air bersih atau air minum merupakan kebutuhan dasar yang sangat penting untuk kesehatan dan kelangsungan hidup manusia. Air dalam tubuh manusia memiliki komposisi di beberapa bagian seperti otak yang terdiri dari $74 \%$ air, otot sekitar $75,6 \%$, darah 
mengandung 83\%, dan ginjal $82,7 \%$, bahkan tulang mengandung 22\% air (Andika,D.2013). Kebutuhan air minum yang dibutuhkan per orang per hari sebanyak 10 liter menurut piramida standar minimum kebutuhan air (Hursany D. 2010). Dengan pesatnya pertumbuhan penduduk terutama di wilayah kepulauan kecil menyebabkan permintaan air bersih atau air minum akan semakin bertambah. Selain air bersih yang diperoleh dari air tanah, masyarakat juga melakukan transaksi jual beli air minum dari kota terdekat ke pulau. Pemenuhan air bersih dari air tanah sangatlah terbatas dan kurang memenuhi dalam persyaratan air minum. Kondisi ini menjadikan sumber air seperti pemanfaatan dan pengolahan air hujan sebagai alternatif yang perlu dipertimbangkan, sehingga dapat mengurangi pengambilan air tanah dan mengurangi biaya transaksi jual beli air minum dari kota ke pulau. Pemanfaatan kembali sumber daya air menjadi hal yang sangat penting di suatu Pulau. Menurut Yulistyorini. A (2011) saat ini sekitar 20\% penduduk dunia mengalami kekurangan air bersih, pencemaran air diperkirakan berdampak pada kesehatan 1,2 milyar penduduk dunia dan mengakibatkan 15 juta kematian pada anak-anak, penggunaan air tanah yang berlebihan menghasilkan penurunan muka air tanah dan mengakibatkan intrusi air laut, manusia cenderung bergantung pada sumber air yang tercemar sebagai sumber air baku, permasalahan air menjadi isu nasional maupun internasional di banyak negara di dunia. Beberapa permasalahan tersebut seharusnya membuat kita memperhatikan ketersediaan sumber air bersih,

Menampung air hujan yang jatuh dianggap salah satu cara yang paling efektif dalam mengatasi permasalahan air. Namun, untuk dapat menampung air hujan dengan maksimal dan juga memenuhi kualitas air yang baik agar nantinya dapat digunakan kembali perlu adanya sistem pemanenan air hujan yang baik. Pemanenan air hujan dapat dilakukan dalam berbagai skala, yaitu skala individu, skala komunal hingga skala yang lebih luas (Nazharia, C., Maryati, S. 2011). Menurut Waskom R. dan Kallenberger J. (2014), pemanenan air hujan merupakan proses pencegahan limpasan air hujan secara langsung dan memasukkannya ke penampungan untuk dimanfaatkan namun hujan di daerah perkotaan dan industri mengandung berbagai kotoran yang diserap dari atmosfer, termasuk arsen dan mercury.

Air yang dikonsumsi oleh
masyarakat harus memenuhi syarat
kesehatan karena air merupakan media
paling baik untuk berkembangnya
mikroorganisme. Pengolahan air untuk
memperoleh air yang memenuhi


persyaratan perlu dilakukan. Tahapantahapan dalam proses pengolahan air adalah penyimpanan, penyaringan dan klorinasi (Chandra, B., 2007).

Pengolahan air hujan telah diteliti pada beberapa peneliti sebelumnya, Susianah,T. dan Masduqi,A. (2011), meneliti mengenai Air Hujan sebagai Alternatif Pemenuhan Kebutuhan Air Minum di Kecamatan Ranuyoso Kabupaten Lumajang. Dari penelitian tersebut disimpulkan bahwa dari analisis aspek teknis diketahui bahwa pengolahan air hujan yang dibutuhkan hanya berupa penyaringan dan pengendapan, kecuali kandungan Koliformnya. Bakteri ini bisa dihilangkan dengan merebus air tersebut sebelum diminum. Mariana,C.M.dkk (2006), meneliti tentang sistem pengolahan air hujan dengan menggunakan teknologi membran dan lampu ultraviolet serta penerapannya dalam kehidupan sehari-hari. Dari hasil penelitian air hujan sesudah melewati proses pengolahan, memiliki kualitas lebih baik dibanding sebelum proses pengolahan. Terjadi peningkatan nilai $\mathrm{pH}$ dan konduktivitas listrik. Sedangkan turbiditas dan kontaminan/zat pencemar dalam air hujan, dapat dikurangi. Tujuan penelitian ini dilakukan untuk mengatasi kekurangan air bersih atau air minum di Pulau Lae-Lae dengan melakukan pengolahan yang sederhana, murah dan aman.

\section{BAHAN DAN METODE}

\section{Lokasi Penelitian}

Model pemanenan dan pengolahan air hujan dilaksanakan di Pulau Lae-Lae Kelurahan Lae-lae Kecamatan Ujung Pandang Kota Makassar dan Laboratorium Balai Kesehatan Makassar. Waktu yang diperlukan untuk melakukan penelitian ini adalah 6 bulan, meliputi persiapan, perancangan, pemasangan, dan pengujian system pemanenan dan pengolahan, serta penyusunan laporan.

\section{Bahan dan Alat}

Bahan dan alat yang digunakan untuk merancang sistem pengolahan air hujan dalam penelitian ini adalah reservoir , saringan jala, pipa, tabung, dakron, dan pengatur aliran air (valve). Sedangkan penunjangnya meliputi air hujan dan bahan/alat yang berkaitan dengan proses karakterisasi/uji kelayakan seperti sodium bikarbonat untuk pengujian parameter kimia.

\section{Metode Pelaksanaan}

Tahap persiapan : Berupa observasi atau pengamatan secara langsung di lapangan, penghitungan volume curah hujan rata-rata tertinggi pada lokasi penelitian dan pengambilan sampel air hujan tanpa melalui proses pengolahan. 
Tahap Perancangan : Menyiapkan bahan dan alat untuk merancang system pemanenan dan pengolahan air hujan. Sistem pengolahan dilakukan dengan metode pra eksperimen dengan menambahkan zat kimia pada tabung yang telah tersusun dakron, kertas saring dan kerikil yaitu penambahan serbuk serbuk sodium bikarbonat sebanyak $0,1 \mathrm{~g} / \mathrm{l}$.

Tahap Pengamatan : Pengamatan dilakukan untuk menguji kelayakan hasil pemanenan dan pengolahan air hujan. Kelayakan pengolahan didasarkan pada perbandingan karakterisasi air hujan sebelum dan setelah diolah menggunakan sistem penyaringan dan pengolahan dengan menambahkan sodium bikarbonat. Uji kelayakan air hujan meliputi parameter yang sesuai berdasarkan syarat kualitas air minum.

Analisis Data : Analisis data dilakukan untuk mengetahui kelayakan sistem pemanenan dan pengolahan air hujan yang telah dirancang yaitu dengan menguji air hujan yang telah melewati model pemanenan dan pengolahan kemudian air hujan tersebut dilakukan uji parameter kualitas air berdasarkan baku mutu air minum.

\section{HASIL PENELITIAN}

Sistem Pemanenan Air Hujan
Perancangan sistem pemanenan di lakukan setelah melakukan observasi dan menentukan volume penampungan yang akan disediakan. Dalam penentuan volume penampungan perlu diketahui besarnya potensi ketersediaan air hujan dan besarnya kebutuhan air yang digunakan.

1. Menentukan rata-rata curah hujan Pada penentuan ini digunakan satu stasiun curah hujan yang terdekat dan paling berpengaruh terhadap lokasi penelitian selama 10 tahun (2005-2014) dengan menggunakan metode basic year. Maka di dapatkan tahun pengamatan curah hujan bulanan dengan rata-rata curah hujan selama satu tahun yang di tunjukkan pada Tabel.1

Tabel.1 Rata-rata curah hujan bulanan

\begin{tabular}{|c|c|}
\hline Bulan & $\begin{array}{c}\text { Rata-rata curah } \\
\text { hujan (mm) }\end{array}$ \\
\hline Januari & 982 \\
\hline Februari & 418 \\
\hline Maret & 336 \\
\hline April & 270 \\
\hline Mei & 137 \\
\hline Juni & 275 \\
\hline Juli & 94 \\
\hline Agustus & 1 \\
\hline September & 2 \\
\hline Oktober & 24 \\
\hline November & 203 \\
\hline Desember & 675 \\
\hline
\end{tabular}


Sumber: BMKG, Stasiun Maritim

Paottere,Makassar

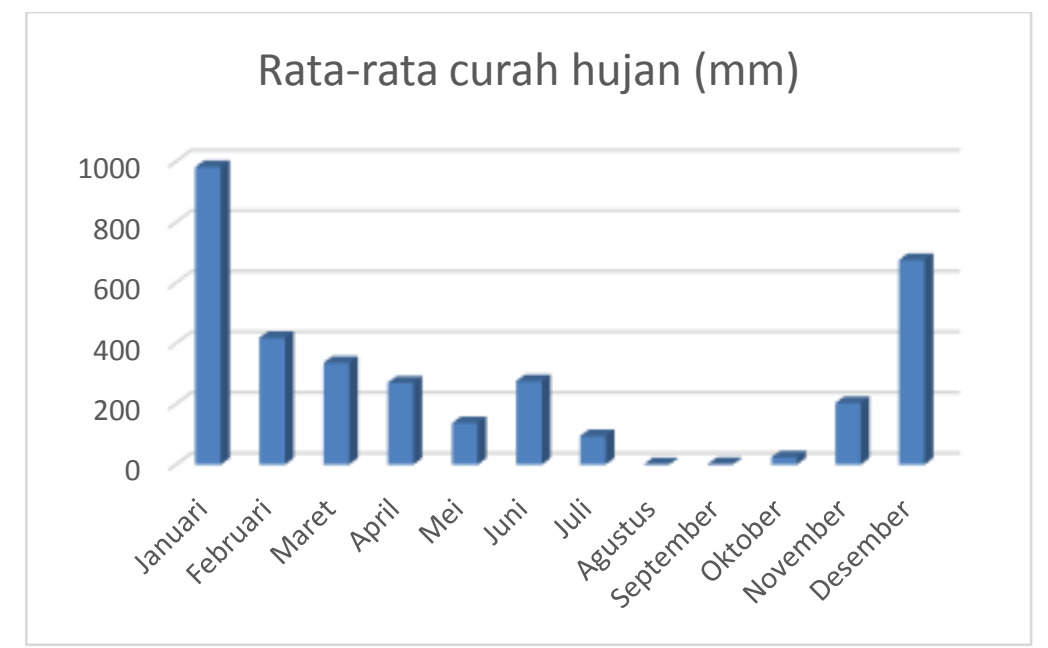

Gambar. 1 Rata-rata curah hujan bulanan

2. Perhitungan ketersediaan air

Perhitungan ini dilakukan untuk mengetahui besarnya volume penampungan yang akan disediakan, Burgess.B (2012). Dimana dalam hal pemanenan, air hujan tidak sepenuhnya dapat di tangkap akibat adanya beberapa penyebab dari hilangnya air hujan yaitu akibat adanya proses first flushing, pengaruh angin, tumpahan dari talang dan curah hujan yang sangat sedikit (gerimis), maka di asumsikan koefisien aliran air hujan adalah 90\% dengan luas area tangkapan 114,75m2. Maka ketersediaan air hujan dapat di hitung dengan menggunakan perhitungan debit andalan dimana data yang dibutuhkan adalah data curah hujan bulanan yang telah diurut dari rata-rata curah hujan terbesar ke terkecil, dengan metode Basic Year pada data ke-m

$$
\mathrm{M}=0,20 \times \mathrm{N}
$$

dengan :

$\mathrm{N}=$ jumlah data

- Intensitas Curah hujan Metode Mononobe

$I=\frac{R 24}{24}\left(\frac{24}{t}\right)^{2 / 3}$

dengan :

I : Intensitas curah hujan (mm/jam)

R24 : Curah hujan maksimum harian selama 24 jam $(\mathrm{mm})$

t : Lamanya hujan (24 jam)

- $\mathrm{Q}$ andalan $80 \%=\mathrm{C} \times \mathrm{I} \times \mathrm{A}$ dengan:

$\mathrm{C}=$ koefisien pengaliran $(0,9)$

$\mathrm{I}=$ Intensitas curah hujan (mm) 


$$
\mathrm{A}=\text { Luasan area tangkapan }\left(\mathrm{m}^{2}\right)
$$

\section{Perhitungan kebutuhan air}

Pada perhitungan ini bertujuan untuk mengetahui banyaknya air hujan yang akan digunakan. Untuk mengetahui kebutuhan air dalam $1 \mathrm{KK}$ pada lokasi penelitian dengan jumlah kebutuhan air per orang menurut Abraham Mashlow's (1908-1970) dalam WHO tentang minimum water quantity for domestic uses kebutuhan air minum per orang per hari adalah 10 liter/orang/hari maka kebutuhan air dapat dihitung dengan persamaan :

$\mathrm{B}=\mathrm{D} \times \mathrm{P} \times 30$

dengan :

B: Total kebutuhan air dalam satu bulan $\left(\mathrm{m}^{3}\right)$

D: Kebutuhan air satu orang dalam satu hari $\left(\mathrm{m}^{3}\right)$

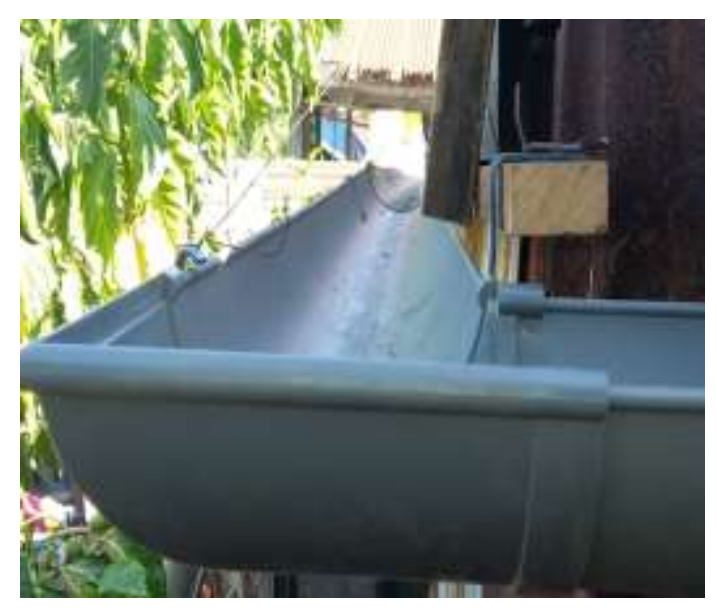

Gambar 2. Talang Air Hujan
P: Jumlah pengguna (jiwa)

$$
30 \text { : jumlah hari dalam satu bulan }
$$

\section{Sistem Pengolahan Air Hujan}

Pada sistem pengolahan air hujan ini digunakan proses pembersihan awal first flushing) saat terjadi hujan pertama kemudian akan dilakukan berupa penyaringan sebelm memasuki penampungan utama dan penampungan kelebihan air hujan (overflow). Pada proses pengolahan terakhir dilakukan penyaringan dan pengolahan berupa pencampuran zat kimia dalam sebuah tabung kecil yang tersusun atas beberapa lapisan material berupa dakron, kertas saring dan $\mathrm{CaHCO}_{3}$ atau sodium bikarbonat $0,1 \mathrm{~g} / \mathrm{l}$. Pada sistem pengolahan ini dapat di lihat pada gambar berikut:

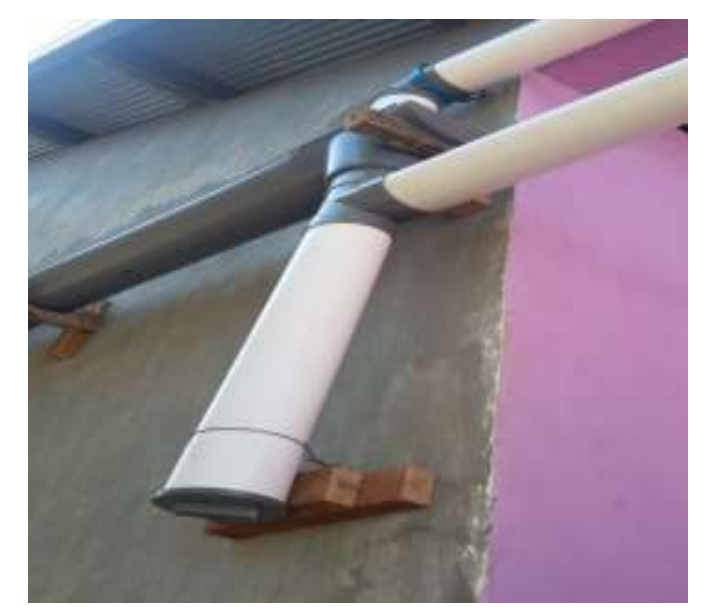

Gambar 3. Pipa Pembuangan Air
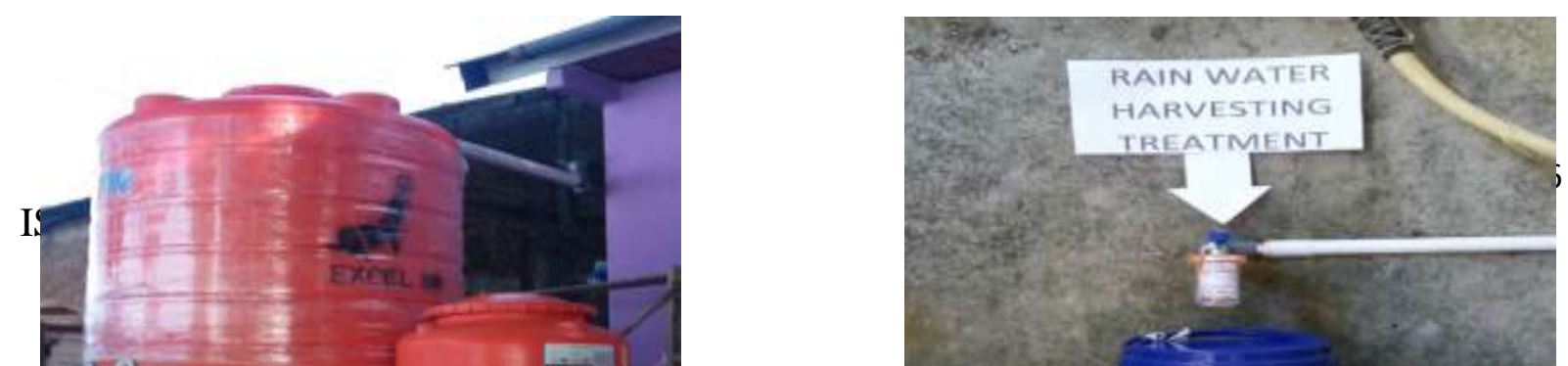
Gambar 4. Penampungan Air

\section{Pembahasan}

Dalam proses pemanenan dan pengolahan air hujan menjadi air minum , terlebih dahulu perlu diketahui kondisi pada lokasi pemanenan air hujan dan karakteristik dari air hujan yang akan di olah. Karakteristik air hujan dapat diketahui dengan melakukan proses pengujian laboratorium terhadap beberapa parameter yang disyaratkan agar dapat memenuhi standar baku mutu air minum.

Kualitas air hujan sangat baik, hampir tidak mengandung kontaminan namun dalam hal pemanenan air hujan tentunya air hujan yang jatuh dan akan di panen mengalami kontak dengan beberapa material yang ada di sekitarnya baik melalui udara, area tangkapan hujan (atap rumah), pipa-pipa distribusi air hujan dan penampungan. Menurut Khaeruddin,D.N.
Gambar 5. Pengolahan Air Hujan dkk (2013), kapasitas bak penampung yang akan disediakan ditentukan berdasarkan tinggi curah hujan per tahun, luas bidang penangkap air, kebutuhan pokok pemakaian air dan jumlah hari kemarau.

Dalam pengolahan air hujan sebagai air minum diharapkan mempertimbangkan beberapa hal yang tidak merugiakan pemakai dimana pertimbanganpertimbangan yang di ambil adalah berupa besarnya biaya yang dibutuhkan dalam pengolahan, kemudahan pengoperasian, kemudahan dalam pemeliharaan instalasi, dan efisiensi pengolahan untuk mendapatkan yang sesuai standar.

Berdasarkan hasil pengujian parameter air hujan sebelum dilakukan pengolahan didapatkan beberapa parameter yang belum memnuhi syarat sebagai air minum, air hujan yang akan dijadikan air minum sebelum pengolahan belum memenuhi syarat air minum dan setelah dilakukan pengolahan mengalami 
perubahan yang berarti seperti pada parameter $\mathrm{pH}$ dari 6,41 meningkat menjadi 7,19 ,parameter flourida mengalami penurunan dari 2,09 menjadi 1,46 dan pada parameter kekeruhan juga mengalami sedikit penurunan namun masih belum memenuhi persyaratan kualitas air minum. Sedangkan untuk parameter warna, MPN Coliform dan MPN E-coli tidak mengalami perubahan yang berarti sehingga dalam penanganan dari parameter mikrobiologi sebaiknya dilakukan secara tradisional yaitu di rebus. Sebelum dilakukan pengolahan air hujan diharapkan penampungan berisi \pm 2000 liter agar terjadi pengenceran terhadap beberapa parameter yang berpengaruh seperti pada parameter warna dan kekeruhan.

Tabel 1. Hasil karakteristik air hujan sebelum dan setelah pengolahan

\begin{tabular}{|c|c|c|c|c|c|}
\hline No & Parameter & Satuan & $\begin{array}{l}\text { Sampel Uji } \\
\text { Sebelum } \\
\text { Pengolahan }\end{array}$ & $\begin{array}{l}\text { Sampel Uji } \\
\text { Setelah } \\
\text { Pengolahan }\end{array}$ & $\begin{array}{c}\text { Standar Baku } \\
\text { Mutu Air Minum } \\
\text { Permekes No.492 } \\
\text { Tahun } 2010\end{array}$ \\
\hline I. & Fisika & & & & \\
\hline 1 & Warna & $\begin{array}{c}\text { Units } \\
\text { PtCo/Color }\end{array}$ & 30 & 7,5 & 15 \\
\hline 2 & Kekeruhan & NTU & 10,2 & 1,66 & 5 \\
\hline II. & Kimia & & & & \\
\hline 3 & $\begin{array}{l}\text { Derajat } \\
\text { Keasaman }(\mathrm{pH})\end{array}$ & - & 6,41 & 7,11 & $6,5-8,5$ \\
\hline 4 & Floride $(\mathrm{F})$ & & 2,09 & 1,46 & 1,5 \\
\hline III & Mikrobiologi & & & & \\
\hline 6 & Total Coliform & $\begin{array}{c}\text { Colony/100 } \\
\mathrm{ml}\end{array}$ & 2419,6 & 0 & 0 \\
\hline 7 & E.Coli & $\begin{array}{c}\text { Colony/100 } \\
\mathrm{ml}\end{array}$ & 2419,6 & 0 & 0 \\
\hline
\end{tabular}

Sumber: Hasil penelitian laboratorium kesehatan, Makassar.

\section{Kesimpulan dan saran}

Besarnya potensi air hujan yang dapat di tampung dapat di tentukan dengan persamaan debit andalan berdasarkan intensitas curah hujan, koefisien pengaliran dan luasnya area tangkapan yang digunakan untuk memanen dalam hal ini area tangkapan yang digunakan adalah luas area atap rumah. Air hujan sebelum dilakukan pengolahan memiliki beberapa parameter yang tidak memenuhi syarat untuk dijadikan air bersih atau air minum diantaranya nilai pH, Warna, Kekeruhan, Flouride, dan mikrobiologi. Secara kuantitas curah hujan yang terjadi pada lokasi penelitian dikatakan mampu untuk memenuhi kebutuhan air minum dalam satu kepala keluarga.

\section{DAFTAR PUSTAKA}

Andhika D. dkk. 2013. Kadar Sisa Chlor Dan Kandungan Bakteri E.Coli Perusahaan Air Minum Tirta Moedal Semarang Sebelum dan Sesudah Pengolahan.Journal Of 
Public Health, 2013, vol 2, number 2.

Burgess B. 2012. Residential Rainwater Harvesting Design and Installation. British Columbia. Canada.

Chandra B. 2007. Pengantar Kesehatan Lingkungan. Jakarta : Penerbit Buku Kedokteran EGC.

Hursany, D. 2010. Pengadaan Air Bersih di Pulau Kodingareng, Kec. Ujung Tanah, Kota Makassar. Universitas Hasanuddin, Makassar.

Khaeruddin,D.N., $\quad$ Proborini,W.D., Pandulu,G.D. 2013. Efisiensi Pembangunan Penampungan Air Hujan Terhadap Pemanfaatan Air Komersil dan Drainase Pada Rumah Toko, Apartemen dan Gedung di kota Malang. Teknik Sipil. Universitas Negeri Malang

Mariana C. M. dkk. 2006. Perancangan Sistem Pengolahan Air Hujan Dengan Menggunakan Teknologi Membran Dan Lampu Ultraviolet Serta Penerapannya Dalam Kehidupan Sehari-Hari. Departemen Fisika. Institut Pertanian Bogor.

Nazharia,C. dan Maryati,S. 2011. Perencanaan Sistem Pengolahan Air Hujan Dengan Menggunakan Teknologi Membran dan Lampu Ultraviolet Serta Penerapannya Dalam Kehidupan Sehari-hari. Jurnal Perencanaan Wilayah dan Kota B SAPPK V2N1. Institut Pertanian Bogor.Waskom R. dan Kallenberger J. (2014)

Susianah T. dan Masduqi A. 2011. Air Hujan Sebagai Alternatif Pemenuhan Kebutuhan Air Minum Di Kecamatan Ranuyoso Kabupaten Lumajang. Teknik Lingkungan. Institut Teknologi Surabaya.

Waskom R. and Kallenberger J. 2014. Graywater Reuse and Rainwater Harvesting. Colorado Water Institute Fact Sheet No.6.702 Revised 12/14. Colorado state university.
Yulistyorini A. 2011. Pemanenan Air Hujan Sebagai Alternatif Pengelolaan Sumber Daya Air di Perkotaan. Teknologi dan Kejuruan vol. 34, no. 1. Universitas Negeri Malang. 